\title{
Article
}

\section{TwinsMX: Uncovering the Basis of Health and Disease in the Mexican Population}

\author{
Ana V. Leon-Apodaca ${ }^{1, \star}$, Enrique Chiu-Han ${ }^{2, \star}$, Ivett Ortega-Mora ${ }^{3, \star}$, Talía V. Román-López ${ }^{3}$, Ulises Caballero-Sánchez ${ }^{3}$, \\ Oscar Aldana-Assad ${ }^{1}$, Adrián I. Campos ${ }^{4,5}$, Gabriel Cuellar-Partida ${ }^{6}$, Alejandra E. Ruiz-Contreras ${ }^{3, \dagger}$, Sarael Alcauter ${ }^{2, \dagger}$, \\ Miguel E. Rentería ${ }^{4,5, \dagger}$ and Alejandra Medina-Rivera ${ }^{1, \dagger}$ \\ ${ }^{1}$ Laboratorio Internacional de Investigación sobre el Genoma Humano, Universidad Nacional Autónoma de México, Querétaro, México, ${ }^{2}$ Instituto de \\ Neurobiología, Universidad Nacional Autónoma de México, Querétaro, México, ${ }^{3}$ Laboratorio de Neurogenómica Cognitiva, Coordinación de Psicobiología y \\ Neurociencias, Facultad de Psicología, Universidad Nacional Autónoma de México, Ciudad de México, México, ${ }^{4}$ QIMR Berghofer Medical Research Institute, \\ Brisbane, QLD, Australia, ${ }^{5}$ Faculty of Medicine, The University of Queensland, Brisbane, QLD, Australia and ${ }^{6}$ Diamantina Institute, University of Queensland, \\ Brisbane, QLD, Australia
}

\begin{abstract}
TwinsMX is a national twin registry in Mexico recently created with institutional support from the Universidad Nacional Autónoma de México. It aims to serve as a platform to advance epidemiological and genetic research in the country and to disentangle the genetic and environmental contributions to health and disease in the admixed Mexican population. Here, we describe our recruitment and data collection strategies and discuss both the progress to date and future directions. More information about the registry is available on our website: https:// twinsmxofficial.unam.mx/ (content in Spanish).
\end{abstract}

Keywords: Mexico; twin registry; admixed population

(Received 23 October 2019; accepted 29 October 2019; First Published online 14 January 2020)

Twin studies are a valuable resource for epidemiological and genetics research. They enable the identification of genetic and environmental contributions to individual variation in complex traits and diseases (Hur \& Craig, 2013). Many countries, predominantly in Europe, North America and Asia, have established twin registries to facilitate the investigation of a wide range of aspects of human health and behavior (Bjerregaard-Andersen et al., 2013; Ferreira et al., 2016; Hur \& Craig, 2013; Marcheco-Teruel et al., 2013). However, there is a dearth of studies in admixed populations, which exhibit distinct genetic architectures due to their complex history of genetic admixture and being subjected to distinct environmental factors.

Historically, research in genetics has been primarily focused on populations of European ancestry. For instance, genomewide association studies (GWAS) have greatly improved our understanding of the genetic basis of complex diseases, such as Alzheimer's disease, multiple sclerosis or type 2 diabetes, over the last decade (Bustamante et al., 2011; Need \& Goldstein, 2009; Popejoy \& Fullerton, 2016). However, as of 2009, 96\% of participants in GWAS studies were of European descent, while Hispanic and Latinos represented only .06\%. By 2016, the proportion of individuals

Authors for correspondence: Alejandra Medina-Rivera, Email: amedina@liigh. unam.mx and Miguel E. Rentería, Email: miguel.renteria@qimrberghofer.edu.au

*These authors contributed equally to this work.

${ }^{\dagger}$ These authors jointly led and supervised the project.

Cite this article: Leon-Apodaca AV, Chiu-Han E, Ortega-Mora I, Román-López TV, Caballero-Sánchez U, Aldana-Assad O, Campos AI, Cuellar-Partida G, RuizContreras AE, Alcauter S, Rentería ME, and Medina-Rivera A. (2019) TwinsMX: Uncovering the Basis of Health and Disease in the Mexican Population. Twin Research and Human Genetics 22: 611-616, https://doi.org/10.1017/thg.2019.112 of non-European descent had increased to nearly $20 \%$, mainly due to more studies being conducted in populations of Asian ancestry (Popejoy \& Fullerton, 2016), but admixed populations, Hispanic and Indigenous people are still, to date, underrepresented. In the long run, a lack of representation might result in inequitable access to the benefits of precision medicine, exacerbating existing disease and healthcare disparities (Martin et al., 2019; Peterson et al., 2019; Wojcik et al., 2019)

The heritability of a trait, that is, the amount of variance of the trait that can be attributed to genetic factors, is a populationspecific parameter. For instance, the heritability of generalized anxiety disorder symptoms has been estimated at $14 \%$ in individuals of European ancestry (Otowa et al., 2016); however, a recent study in a sample of Hispanic participants living in the USA showed a heritability of 7.2\% (Dunn et al., 2017), suggesting that dissimilar genetic influences are in place. The question still remains whether similar heritability estimates will be identified for Hispanic populations living in environmentally diverse countries of Latin America.

Advantages of integrating diverse populations in genetic association studies include the possibility for uncovering novel population-specific genetic variants implicated in disease and drug response (Mills \& Rahal, 2019) and aiding in the fine mapping of disease risk loci (Gonzalez et al., 2016). Therefore, there is growing interest among the scientific community in increasing ethnic diversity in genetic studies. To that end, establishing populationbased deeply phenotyped and genotyped cohorts in Latin America is a paramount step. 
Mexico is culturally and ethnically diverse. Its population has a complex admixed genetic makeup, with contributions from European, Native American and African and, to a lesser degree, East-Asian ancestry populations (Moreno-Estrada et al., 2014). Similarly, genetic stratification among Indigenous populations within Mexico is striking, with some groups being as differentiated as Europeans are from East Asians (Moreno-Estrada et al., 2014). Thus, twin studies in the Mexican population could contribute substantially to our understanding of the genetic and environmental mechanisms that underlie ethnic variation in complex traits and diseases, including metabolic, cardiovascular and mental diseases, or behavioral, psychometric and anthropometric traits. This reasoning is what inspired the creation of TwinsMX, a populationbased registry of Mexican twins.

TwinsMX was founded in 2018 as a national twin registry in Mexico, with the electronic questionnaires portal opening for registrations in May 2019. Its primary aim is to establish one of the largest deeply phenotyped population-based cohort studies with a genetically informative design in an admixed population. The core research team is multidisciplinary, comprising experts in bioinformatics, psychology, neuroscience and genetics. The required infrastructure and institutional support has been provided by National Autonomous University of Mexico (UNAM), the premier research university in the country, and technical advisory during the creation process was facilitated by Mexican geneticists working with the Queensland Twin Registry in Brisbane, Australia. Collaborations with other twin registries in Latin America and around the world are underway. TwinsMX will contribute significantly to expand our knowledge of the genetics of admixed populations and will lay the foundations for a larger national longitudinal biobank with associated genotyping and biological samples in the future.

\section{Experimental Design and Progress to Date}

\section{Target Population and Estimates}

Our target population consists of twins, triplets and members of any multiple births from all over Mexico. Data from Mexico's National Statistics and Geography Institute (INEGI, in Spanish) indicate that there are approximately 750,000 twin-pairs aged between 18 and 60 in the country. In a first stage, the goal of TwinsMX is to recruit 15,000 individuals ( 7500 twin-pairs). Official data from the National Intercensal Survey of 2015 indicate that the State of México, Mexico City, Veracruz, Jalisco, Puebla and Guanajuato are the states with the highest number of inhabitants, with $13.5 \%, 7.5 \%, 6.8 \%, 6.6 \%$ and $4.9 \%$ of Mexico's total population, respectively (INEGI, 2015). These states are geographically located within the central region of the country, and thus is where we are focusing our initial recruiting efforts.

\section{Recruitment Strategy}

Participants are being invited via social media (Facebook, Twitter, Instagram) and traditional advertising to engage and participate. We aim to reach the twin and multiple birth population nationwide by actively sharing digital content as part of our publicity campaign. Furthermore, TwinsMX has been featured in radio shows and interviews where members of our research team have been broadcast in national media, giving us the opportunity to talk about the purpose and goals of the project. Notably, an alliance has been established with the National Multiple Births Association, and the official launch of the registry was made at their annual

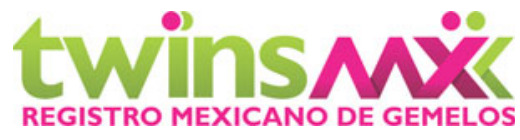

Fig. 1. TwinsMX logo: The Mexican Twin Registry ('Registro Mexicano de Gemelos' in Spanish).

meeting this year. As part of our strategy to recruit a diverse cohort of participants and to promote the project in different regions, we will host information events across the country.

\section{Ethics Approval and Privacy Protection}

The project has been reviewed and approved by the Research Ethics Committee of the Institute of Neurobiology at UNAM in March 2019. Participant registration and data collection are done online through a secure page, and the personal information of all participants is anonymized and stored in a database within a dedicated server at the National Laboratory of Advanced Scientific Visualization at UNAM, under strict security protocols. As declared in the ethics approval, informed consent must be obtained from every participant in the project. New registrations cannot be completed until the participant provides his digital signature granting consent on the use of his or her data. In compliance with the Federal Law on the Protection of Personal Data Held by Private Parties, TwinsMX has a privacy statement that stipulates how personal data will be used, stored and handled, and how users are protected under principles provided by the Mexican federal law.

\section{Institutional Identity and Online Presence}

Our logo (Figure 1) consists of the words 'Twins' and 'MX', and 'Mexican Twin Registry' (in Spanish, 'Registro Mexicano de Gemelos'), located right below. The 'I' in the word 'Twins' and the ' $\mathrm{X}$ ' in the ' $\mathrm{MX}$ ' simulate two heads and bodies, making reference to twin-pairs. The color scheme, including bright green and pink, was chosen because they both represent the vibrancy of our culture, as well as the charisma of our people. Mexicans regard that specific tone of pink as 'Mexican pink'. Along with the green, these colors have been used in traditional Mexican clothing, textiles and artisanal objects and, therefore, resemble the Mexican spirit and its people. The TwinsMX logo is currently under the registration process as a trademark and securing copyrights related to its exclusive use and distribution within the Mexican territory.

Our website was designed in accordance with the same color scheme used in the logo. Additionally, it features photographs from twins and multiple birth members at an event hosted by the National Multiple Births Association in Jalpan, Querétaro, where we officially launched the project and began recruiting participants. The site features two buttons that redirect potential participants to the registration page and surveys implemented in the Research Electronic Data Capture (REDCap) platform (Harvey, 2018; Wright, 2016). The site includes an 'About Us' ('Acerca de' in Spanish) section, links to the privacy statement and 'Frequently Asked Questions'. Furthermore, the site has a 'Contact Us' button that displays a map with the location of our laboratory at UNAM in Querétaro, our contact information and a message box that allows visitors to get in touch with our research team. Finally, we also have a presence in social networks, including Facebook, Twitter and Instagram; people can find us under "\% TwinsMXOfficial' and follow us for news and updates about 
Table 1. Overview of the contents in the core module

\begin{tabular}{|c|c|}
\hline Section & Description \\
\hline $\begin{array}{l}\text { Sociodemographic } \\
\text { variables }\end{array}$ & $\begin{array}{l}\text { Instruments requesting personal information such } \\
\text { as full name, date of birth and contact information, } \\
\text { as well as occupation, level of education of } \\
\text { participants and both parents, and amount of the } \\
\text { family's income in minimum wages to assess the } \\
\text { sociodemographic composition of our sample. }\end{array}$ \\
\hline Zygosity & $\begin{array}{l}\text { A short questionnaire that evaluates the similitude } \\
\text { of phenotypic physical traits and the frequency that } \\
\text { their relatives confound twins. This questionnaire } \\
\text { identifies if twins are identical (monozygotic) or } \\
\text { nonidentical (dizygotic) with an accuracy of } 98 \% \\
\text { (Ordoñana et al., 2013). }\end{array}$ \\
\hline Laterality & $\begin{array}{l}\text { Questionnaire ascertained by the Edinburgh } \\
\text { Handedness Inventory (Oldfield, 1971). }\end{array}$ \\
\hline Medical history & $\begin{array}{l}\text { Checklist of personal and family history of } \\
\text { cardiovascular, metabolic, endocrine, neoplastic, } \\
\text { respiratory, psychiatric, neurologic, urinary, } \\
\text { reproductive, gastrointestinal, rheumatologic, } \\
\text { developmental, pregnancy, dermatologic, and } \\
\text { ophthalmologic disorders as well as questions } \\
\text { addressing surgical history and medication use. }\end{array}$ \\
\hline
\end{tabular}

Table 2. Overview of the contents in the secondary module

\begin{tabular}{|c|c|}
\hline Section & Description \\
\hline Personality traits & $\begin{array}{l}\text { Instruments assessing personality traits in various } \\
\text { dimensions, such as the Big Five Personality } \\
\text { inventory (Boyle et al., 2008), Behavioral Activation } \\
\text { System and Behavioral Inhibition System (Muris } \\
\text { et al., 2005). }\end{array}$ \\
\hline $\begin{array}{l}\text { Substance use } \\
\text { and abuse }\end{array}$ & $\begin{array}{l}\text { Questionnaires characterizing frequency and amount } \\
\text { of drug use focusing on tobacco (Fagerstrom test; } \\
\text { Heatherton et al., 1991), alcohol (Alcohol Use } \\
\text { Disorders Identification Test, AUDIT; Babor et al., } \\
\text { 1992), and cannabis (Cannabis Use Disorders } \\
\text { Identification Test, CUDIT) (Adamson \& Douglas } \\
\text { Sellman, 2003), but also inquiring about } \\
\text { consumption of other drugs, as well as instruments } \\
\text { focusing on substance use disorder identification. }\end{array}$ \\
\hline Mental health & $\begin{array}{l}\text { Instruments inquiring about state and trait } \\
\text { symptomatology in relation to mental health, that is, } \\
\text { State-Trait Anxiety Inventory (State-Trait Depression } \\
\text { Inventory; Martín-Carbonell et al., 2012); paranoid } \\
\text { ideation, psychoticism, and others (Cavia, 2016). }\end{array}$ \\
\hline $\begin{array}{l}\text { Diet and eating } \\
\text { behaviors }\end{array}$ & $\begin{array}{l}\text { Instruments inquiring about attitudes toward food } \\
\text { intake and food-related behaviors, with some } \\
\text { questions oriented to traits suggestive of eating } \\
\text { disorders (Fadanelli, 2014; Garcia, n.d.). }\end{array}$ \\
\hline Physical activity & $\begin{array}{l}\text { Questionnaire that assesses physical activity in three } \\
\text { different contexts: at work, for transport and during } \\
\text { leisure time (World Health Organization, 2005). }\end{array}$ \\
\hline $\begin{array}{l}\text { Lifestyle and } \\
\text { quality of life }\end{array}$ & $\begin{array}{l}\text { Aspects of lifestyle such as sleep quality (Pittsburgh } \\
\text { Sleep Quality Index (Jiménez-Genchi et al., 2008), } \\
\text { perceived health status and functionality in daily life } \\
\text { (Zúniga et al., 1999). }\end{array}$ \\
\hline Cognition & $\begin{array}{l}\text { Web-based implementations of cognitive } \\
\text { performance tasks, for example, 0,1,2-back tasks } \\
\text { (Ruiz-Contreras et al., 2012) and the Eriksen flanker } \\
\text { task (Eriksen \& Eriksen, 1974). }\end{array}$ \\
\hline
\end{tabular}

the project and general information including posters, infographics and photos that stir continuous interaction with the general public.

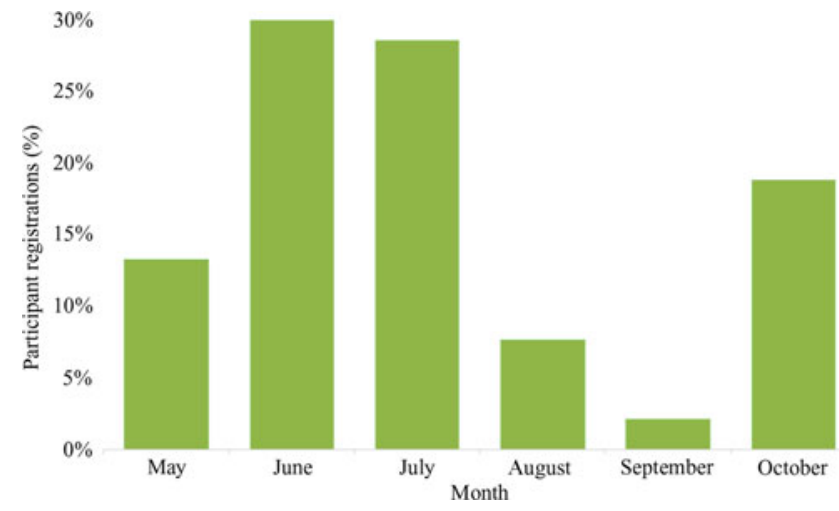

Fig. 2. Monthly registrations since launching the TwinsMX platform in May 2019 (as of October 18, 2019).

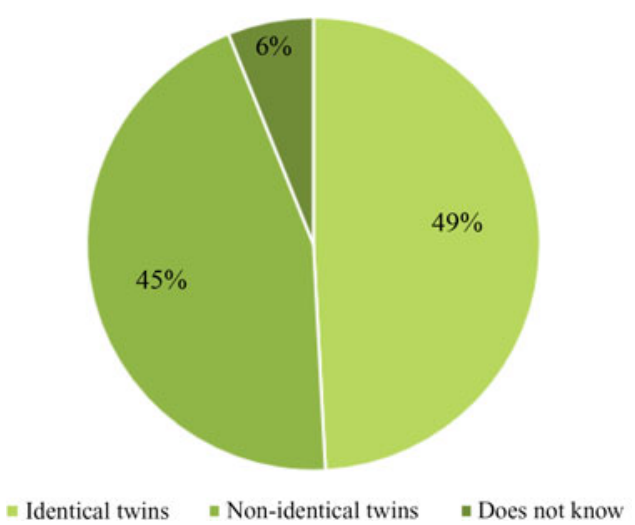

Fig. 3. Self-reported zygosity of registered twin-pairs (as of October 18, 2019).

\section{Data Collection Platform}

Data collection has been conducted using the REDCap platform (Harvey, 2018; Wright, 2016), which enables the integration of several surveys and document collections in research studies while facilitating data management for statistical analysis.

In compliance with Article 55 of the Federal Civil Code in our country, all Mexicans have the legal obligation to register the birth of their children within 6 months following the date of birth of each child born in Mexico. All registered Mexicans are assigned a Unique Population Registry Code (CURP, for the abbreviation of Clave Única de Registro de Población, in Spanish), composed of 18 alphanumeric characters that contain initials and an additional letter from their given and family names, date of birth, sex, state of birth, and a unique number to avoid duplication.

Each participant in TwinsMX is required to enter their CURP as part of their registration process. Given that this code is unique, users can use it as their username in the platform and is used to match twins to their co-twin. This allows participants born and registered in Mexico, but currently living abroad, to participate if they have a CURP. Importantly, the number can only be used by participants to access their information, because data are anonymized in the backend.

\section{Measures Being Collected}

Data collection surveys are structured into two modules (for an overview of contents, see Tables 1 and 2). We have implemented 
(a)

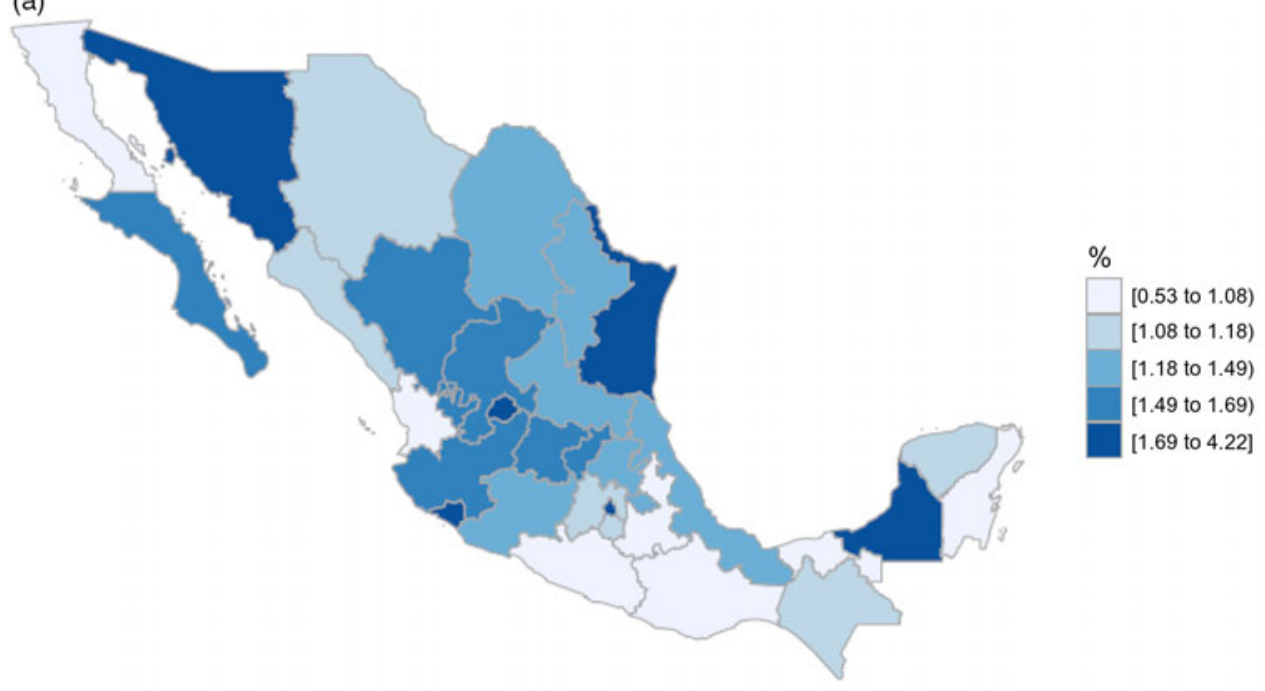

(b)

Fig. 4. (a) Geographical distribution of multiple births in Mexico by State, shown by quintiles (National Institute of Statistics and Geography, 'Birth characteristics', press communication, 2017) and (b) TwinsMX incoming participant registrations as of October 2019.

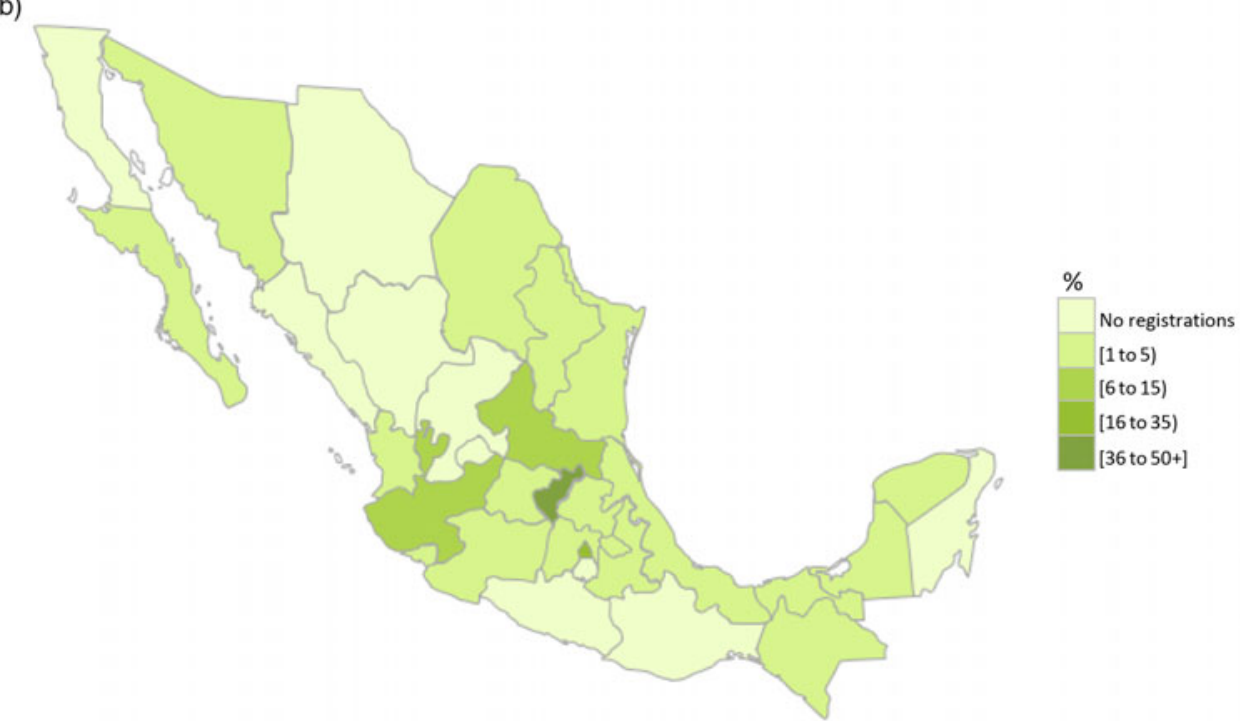

a set of initial surveys about medical family history, zygosity, sociodemographic information, personality, addictions, mental health, eating habits, lifestyle and quality of life variables, validated in the Mexican population. Also, cognitive tests that assess essential cognitive processes, including attention, working and episodic memory, decision-making and impulsivity, are being integrated in the platform. Some of these tasks and questionnaires have previously been used in the Mexican population by Dr Ruiz-Contreras (Ruiz-Contreras et al., 2012) and Dr Alcauter (Alcauter et al., 2017; Gracia-Tabuenca et al., 2018). Participants are asked for permission to be recontacted in the future, to be invited to take part in additional waves of the study and indicate their willingness to provide a DNA sample for genotyping.

\section{Recruitment to Date}

The TwinsMX platform was launched in May 2019. Since then, 145 individuals had successfully signed up as of October 18, 2019 (Figure 2). Of those, 51\% of registered participants are male and $49 \%$ are female; $49 \%$ self-reported being monozygotic pairs, $45 \%$ dizygotic and $6 \%$ do not know (Figure 3 ). We observed an increase in registration numbers from June to July when the research team attended the biggest twin and multiple birth events nationwide. From then on, we had a considerable decrease in numbers from August to September, which led us to launch an improved social media strategy to strengthen our positioning, which resulted in an increase in the number of online registrations during October (Figure 2).

Most registered participants to date come from the state of Querétaro, followed by Mexico City, San Luis Potosí, Jalisco, Guanajuato, Veracruz and the State of Mexico (Figure 4a). Considering the distribution of multiple births across the country (Figure $4 \mathrm{~b}$ ), we believe this trend to be biased by the fact that part of our core research team and the National Multiple Births Association in Mexico are both based in Querétaro, where we have a stronger presence. Nonetheless, we have successfully managed to reach all states across the country via social networks.

\section{Available Infrastructure and Support}

UNAM provides full infrastructure and institutional support for the development and upkeep of TwinsMX as Mexico's National Twin Registry. Our core research team is based in both the main campus in Mexico City (School of Psychology at University City) 
and a satellite campus in the city of Querétaro (International Laboratory for Human Genome Research and Institute of Neurobiology), located $221 \mathrm{~km}$ north-west of Mexico City. Similarly, facilities such as the Unit for Magnetic Resonance Imaging and the National Laboratory of Advanced Scientific Visualization from the UNAM also provide infrastructure and regular support to our twin registry.

\section{Collaborations}

Technical advisory and support during the creation of this twin registry was facilitated by Mexican geneticists working with the Queensland Twin Registry in Brisbane, Australia (Dr Rentería and Dr Cuéllar-Partida), and budding collaborations with other twin registries in Latin America and around the world are underway. Furthermore, the connection with the National Multiple Births Association in Mexico has been extremely valuable and has allowed us to get closer to the community of multiple births.

\section{Future Directions}

As there is only a handful of deeply phenotyped population-based cohorts with genetically informative designs in Latin America, we expect that TwinsMX will play a central role in characterizing the genetic and environmental factors involved in complex traits and diseases in admixed populations. In parallel, we will try to secure funding for DNA collection, genotyping, and to extend the study to include family members of twins, such as parents and siblings. We envision that molecular genetic studies in the Mexican population will provide valuable data for fine mapping of genetic risk variants relevant for many conditions.

A particular interest of the research team is to investigate brain structure and function through magnetic resonance imaging technologies, taking advantage of state-of-the-art facilities available within the National Laboratory of Magnetic Resonance Imaging (Laboratorio Nacional de Imagenología por Resonancia Magnética in Spanish) at the Institute of Neurobiology. Neuroimaging twin studies have been fundamental in understanding the heritability and genetic architecture of brain structure and function (Gao et al., 2014; Jansen et al., 2015; Rentería et al., 2014). In addition, the electrophysiological brain activity evaluated at the School of Psychology will also provide insights about temporal information related to cognitive function. Therefore, there is potential to investigate the genetic relationships of neuroimaging and electrophysiological measures in relation to specific conditions (e.g., addiction, psychiatric disorders, metabolic or cardiovascular conditions).

Overall, we also hope to articulate a network of collaborations with other scientists in Mexico and to actively contribute to the larger international community of genetics consortia. We have already established contact with the Mexican Biobank Project (http://mxbiobankproject.org/), a group of researchers that have already established strong genotyping and analysis pipelines for the Mexican population. Thus, we extend an invitation to all those with common interests to get in contact with us and explore opportunities for collaboration.

Acknowledgments. We would like to thank the Universidad Nacional Autónoma de México for their support for this project and to all the twins who have signed up for their willingness to participate and contribute to medical research. We thank Prof Nick Martin of the QIMR Berghofer Medical Research Institute for valuable input and feedback during the early stages of the creation of the registry; Mauricio Guzman for designing the logo and corporate image for TwinsMX; Patricia Andrade for her support as marketing strategy advisor; the staff responsible for the maintenance of the TwinsMX IT infrastructure, in particular Luis Alberto Aguilar Bautista and Jair García Sotelo at the Laboratorio Nacional de Visualización Científica Avanzada (Mexico); those who have supported us in the selection of surveys and instruments, Dr Luis Pablo Cruz-Hervert from the School of Odontology at UNAM, and Dr Carlos S. Cruz-Fuentes and Dr Gabriela A. Martínez-Levy from Mexico's National Institute of Psychiatry; those that contributed to editing the questionnaires for REDCap: Elissa López, Carla Guillermo-Flores, Angela Polo, Alejandra Lázaro, Andrea Tapia and Sofía Pradel. We especially thank Asociación de Nacimientos Múltiples de México, A.C., particularly Pedro Alfonso Ochoa Ledesma, President of the Association, who has supported the project from the beginning.

Financial support. A.M.-R.'s laboratory is supported by funding from Consejo Nacional de Ciencia y Tecnologia, Mexico (CONACYT) (Grant no. 269449) and by a grant from the Programa de Apoyo a Proyectos de Investigación e Innovación Tecnológica of the Universidad Nacional Autónoma de México (PAPIIT-UNAM; Grant no. IA206517-IA201119); A.E.R.-C.'s laboratory is supported by PAPIIT-UNAM (Grant no. IN217918). S.A. is supported by PAPIIT-UNAM (Grant no. IA204217, IN212219). G.C.-P. is funded by an Australian Research Council (ARC) Discovery Early Career Researcher Award (DE180100976). M.E.R. thanks the support of Australia's National Health and Medical Research Council and the SRC, through a National Health \& Medical Research Council (NHMRC)-ARC Dementia Research Development Fellowship (GNT1102821).

\section{References}

Adamson, S., \& Douglas Sellman, J. (2003). A prototype screening instrument for cannabis use disorder: The Cannabis Use Disorders Identification Test (CUDIT) in an alcohol-dependent clinical sample. Drug and Alcohol Review, 22, 309-315.

Alcauter, S., García-Mondragón, L., Gracia-Tabuenca, Z., Moreno, M. B., Ortiz, J. J., \& Barrios, F. A. (2017). Resting state functional connectivity of the anterior striatum and prefrontal cortex predicts reading performance in school-age children. Brain and Language, 174, 94-102.

Babor, T. F., Delafuente, J. R., \& Saunders, J. (1992). AUDIT: The alcohol use disorders identification test: Guidelines for use in primary health care. Geneva: World Health Organization.

Bjerregaard-Andersen, M., Gomes, M. A., Joaquím, L. C., Rodrigues, A., Jensen, D. M., Christensen, K., . . Sodemann, M. (2013). Establishing a twin registry in Guinea-Bissau. Twin Research and Human Genetics, 16, 179-184.

Boyle, G. J., Matthews, G., \& Saklofske, D. H. (2008). The Sage handbook of personality theory and assessment: Personality theories and models. Los Angeles, CA: Sage.

Bustamante, C. D., Burchard, E. G., \& De la Vega, F. M. (2011). Genomics for the world. Nature, 475, 163-165.

Cavia, S. (2016). 19 Escalas de evaluación psicológica. Retrieved October 2018 from https://www.academia.edu/31038102/19_ESCALAS_DE_EVALUACION_ PSICOLOGICA

Dunn, E. C., Sofer, T., Gallo, L. C., Gogarten, S. M., Kerr, K. F., Chen, C.-Y., ... Smoller, J. W. (2017). Genome-wide association study of generalized anxiety symptoms in the Hispanic Community Health Study/Study of Latinos. American Journal of Medical Genetics. Part B, Neuropsychiatric Genetics, 174, 132-143.

Eriksen, B. A., \& Eriksen, C. W. (1974). Effects of noise letters upon the identification of a target letter in a nonsearch task. Perception \& Psychophysics, 16, 143-149.

Fadanelli, M. del P. B. (2014). Actitud hacia la ingesta y peso corporal. Acta Médica Grupo Ángeles, 12, 181-188.

Ferreira, P. H., Oliveira, V. C., Junqueira, D. R., Cisneros, L. C., Ferreira, L. C., Murphy, K., .. . Teixeira-Salmela, L. F. (2016). The Brazilian twin registry. Twin Research and Human Genetics, 19, 687-691.

Gao, W., Elton, A., Zhu, H., Alcauter, S., Smith, J. K., Gilmore, J. H., \& Lin, W. (2014). Intersubject variability of and genetic effects on the brain's functional connectivity during infancy. The Journal of Neuroscience, 34, 11288-11296.

Garcia, B. (n.d.). 19 Escalas de Evaluacion Psicologica. Retrieved October 14, 2019 from https://www.academia.edu/31038102/19_ESCALAS_DE_ EVALUACION_PSICOLOGICA 
Gonzalez, S., Gupta, J., Villa, E., Mallawaarachchi, I., Rodriguez, M., Ramirez, M., ... Escamilla, M. (2016). Replication of genome-wide association study (GWAS) susceptibility loci in a Latino bipolar disorder cohort. Bipolar Disorders, 18, 520-527.

Gracia-Tabuenca, Z., Moreno, M. B., Barrios, F. A., \& Alcauter, S. (2018). Hemispheric asymmetry and homotopy of resting state functional connectivity correlate with visuospatial abilities in school-age children. NeuroImage, 174, 441-448.

Harvey, L. A. (2018). REDCap: Web-based software for all types of data storage and collection. Spinal Cord, 56, 625.

Heatherton, T. F., Kozlowski, L. T., Frecker, R. C., \& Fagerström, K. O. (1991). The Fagerström test for nicotine dependence: A revision of the Fagerström Tolerance Questionnaire. British Journal of Addiction, 86, 1119-1127.

Hur, Y.-M., \& Craig, J. M. (2013). Twin registries worldwide: An important resource for scientific research. Twin Research and Human Genetics, 16, $1-12$.

Instituto Nacional de Estadística y Geografía (INEGI). (2015). Población. Retrieved October 14, 2019 from https://www.inegi.org.mx/temas/estructura/

Jansen, A. G., Mous, S. E., White, T., Posthuma, D., \& Polderman, T. J. C. (2015). What twin studies tell us about the heritability of brain development, morphology, and function: A review. Neuropsychology Review, 25, 27-46.

Jiménez-Genchi, A., Monteverde-Maldonado, E., Nenclares-Portocarrero, A., Esquivel-Adame, G., \& de la Vega-Pacheco, A. (2008). Confiabilidad y análisis factorial de la versión en español del índice de calidad de sueño de Pittsburgh en pacientes psiquiátricos. Gaceta Medica de Mexico, 144, 491-496.

Marcheco-Teruel, B., Cobas-Ruiz, M., Cabrera-Cruz, N., Lantigua-Cruz, A., García-Castillo, E., Lardoeyt-Ferrer, R., ... Valdés-Sosa, M. (2013). The Cuban twin registry: Initial findings and perspectives. Twin Research and Human Genetics, 16, 98-103.

Martin, A. R., Kanai, M., Kamatani, Y., Okada, Y., Neale, B. M., \& Daly, M. J. (2019). Clinical use of current polygenic risk scores may exacerbate health disparities. Nature Genetics, 51, 584-591.

Martín-Carbonell, M., Riquelme-Marín, A., Ortigosa-Quiles, J., Meda-Lara, R., Cerquera-Córdova, A., Enríquez-Santos, J., \& Pérez-Díaz, R. (2012). Utilidad del Inventario de Depresión Rasgo-Estado (IDERE) para el diagnóstico clínico. Un estudio con muestras de 4 países iberoamericanos. Anales de Psicología, 28, 763-771.

Mills, M. C., \& Rahal, C. (2019). A scientometric review of genome-wide association studies. Communications Biology, 2, Article no. 9.

Moreno-Estrada, A., Gignoux, C. R., Fernández-López, J. C., Zakharia, F., Sikora, M., Contreras, A. V., Bustamante, C. D. (2014). Human genetics. The genetics of Mexico recapitulates Native American substructure and affects biomedical traits. Science, 344, 1280-1285.
Muris, P., Meesters, C., de Kanter, E., \& Timmerman, P. E. (2005) Behavioural inhibition and behavioural activation system scales for children: Relationships with Eysenck's personality traits and psychopathological symptoms. Personality and Individual Differences, 38, 831-841.

National Institute of Statistics and Geography. (2017). Birth characteristics [Press release]. Aguascalientes, Mexico: Author.

Need, A. C., \& Goldstein, D. B. (2009). Next generation disparities in human genomics: Concerns and remedies. Trends in Genetics, 25, 489-494.

Oldfield, R. C. (1971). The assessment and analysis of handedness: The Edinburgh inventory. Neuropsychologia, 9, 97-113.

Ordoñana, J. R., Rebollo-Mesa, I., Carrillo, E., Colodro-Conde, L., GarcíaPalomo, F. J., González-Javier, F., .. Pérez-Riquelme, F. (2013). The Murcia twin registry: A population-based registry of adult multiples in Spain. Twin Research and Human Genetics, 16, 302-306.

Otowa, T., Hek, K., Lee, M., Byrne, E. M., Mirza, S. S., Nivard, M. G., . . Hettema, J. M. (2016). Meta-analysis of genome-wide association studies of anxiety disorders. Molecular Psychiatry, 21, 1391-1399.

Peterson, R. E., Kuchenbaecker, K., Walters, R. K., Chen, C.-Y., Popejoy, A. B., Periyasamy, S., ... Duncan, L. E. (2019). Genome-wide association studies in ancestrally diverse populations: Opportunities, methods, pitfalls, and recommendations. Cell, 179, 589-603.

Popejoy, A. B., \& Fullerton, S. M. (2016). Genomics is failing on diversity. Nature, 538, 161-164.

Rentería, M. E., Hansell, N. K., Strike, L. T., McMahon, K. L., de Zubicaray, G. I., Hickie, I. B., . . . Wright, M. J. (2014). Genetic architecture of subcortical brain regions: Common and region-specific genetic contributions. Genes, Brain, and Behavior, 13, 821-830.

Ruiz-Contreras, A. E., Soria-Rodríguez, G., Almeida-Rosas, G. A., GarcíaVaca, P. A., Delgado-Herrera, M., Méndez-Díaz, M., \& ProspéroGarcía, O. (2012). Low diversity and low frequency of participation in leisure activities compromise working memory efficiency in young adults. Acta Psychologica, 139, 91-96.

Wojcik, G. L., Graff, M., Nishimura, K. K., Tao, R., Haessler, J., Gignoux, C. R., . . Carlson, C. S. (2019). Genetic analyses of diverse populations improves discovery for complex traits. Nature, 570, 514-518.

World Health Organization. (2005). Global Physical Activity Questionnaire (GPAQ). Geneva: Author. Retrieved October 19, 2019 from https://www. who.int/ncds/surveillance/steps/GPAQ\%20Instrument\%20and\%20Analysis \%20Guide\%20v2.pdf

Wright, A. (2016). REDCap: A tool for the electronic capture of research data. Journal of Electronic Resources in Medical Libraries, 13, 197-201.

Zúniga, M. A., Carrillo-Jiménez, G. T., Fos, P. J., Gandek, B., \& MedinaMoreno, M. R. (1999). Evaluación del estado de salud con la Encuesta SF-36: resultados preliminares en México. Salud Pública de México, 41, $110-118$ 